\title{
KARAKTERISASI RESERVOIR KARBONAT DENGAN APLIKASI SEISMIK ATRIBUT DAN INVERSI SEISMIK IMPEDANSI AKUSTIK
}

\author{
Ridho Fahmi Alifudin ${ }^{1)}$, Wien Lestari ${ }^{11}$, Firman Syaifuddin ${ }^{1)}$, M. Wahdanadi Haidar ${ }^{2)}$ \\ 1) Jurusan Teknik Geofisika, FTSP ITS, ${ }^{2)}$ PT Petrochina-Pertamina East Java \\ e-mail: ridhofahmi5@gmail.com
}

\begin{abstract}
Abstrak. Analisis reservoir sangat penting dalam dunia minyak dan gas pada suatu wilayah untuk mengetahui cadangan maupun karakter dari reservoir itu sendiri. Oleh karena itu adanya analisis seismik atribut dan aplikasi seismik inversi dapat membantu interpreter mempermudah dalam menganalisis reservoir. Dari data seismik, geologi dan data sumur, peneliti dapat menganalisis prospek keberadaaan hidrokarbon pada daerah penelitian. Metodologi pengerjaan penelitian ini meliputi tahap pengumpulan data, tahap pengolahan data log dan seismik, interpretasi horizon dan fault, pembuatan time \& depth structure map, analisis atribut seismik dan inversi seismik. Reservoar Karbonat pada lapangan penelitian mempunyai nilai impedansi yang tinggi yaitu $35392-48482\left((\mathrm{ft} / \mathrm{s})^{*}(\mathrm{~g} / \mathrm{cc})\right)$, namun terdapat potensi hidrokarbon pada reservoar dengan nilai impedansi lebih rendah yaitu $30717-34645$ ((ft/s)*(g/cc)).

Kata Kunci: karbonat; atribut seismik; inversi based model; impedansi akustik
\end{abstract}

\begin{abstract}
Reservoir analyzation is so important for oil and gas industry to find out the character and oil reserves from the prospect reservoir. The purposes in this research are to characterize the reservoir with the application of seismic attribute and inversion seismic Acoustic Impedance for JOB Pertamina PetroChina East Java's Field. From seismic data, well data and geological data control that can help us to interpret the character of reservoir. The methodology of this research such as collect the data, seismic well tie, interpret the horizon of top formation, interpret fault, create time and depth structure map, seismic attribute and seismic inversion. Carbonate reservoir in this filed has high impedance acoustic between $35392-48482\left((\mathrm{ft} / \mathrm{s})^{*}(\mathrm{~g} / \mathrm{cc})\right)$, and then there is an anomaly low impedance on this reservoir between $30717-34645\left((\mathrm{ft} / \mathrm{s})^{*}(\mathrm{~g} / \mathrm{cc})\right)$. That anomalies indicate the presence of hydrocarbons.
\end{abstract}

Keywords: seismic interpretation; time \& depth strucure map; seismic attribute; invertion seismic acoustic impedance

\section{PENDAHULUAN}

Keberadaan sumber energi minyak dan gas bumi masih menjadi energi utama dalam mendukung kegiatan manusia. Potensi sumber minyak dan gas masih terus dikembangkan guna memenuhi kebutuhan pasar. Untuk itu kegiatan eksplorasi dan eksploitasi harus terus dikembangkan.

Lapangan ' $R F^{\prime}$ ' merupakan lapangan migas yang berada di Jawa Timur Utara. Terbukti dengan adanya produksi minyak dengan reservoir batuan karbonat umur miosen. Hal ini dibuktikan dari beberapa sumur pengeboran yang berproduksi kontinyu hingga saat ini. Secara stratigrafi, zona reservoir penelitian ditunjukkan pada Gambar 1 dimana litologi didominasi oleh batuan karbonat terumbu.

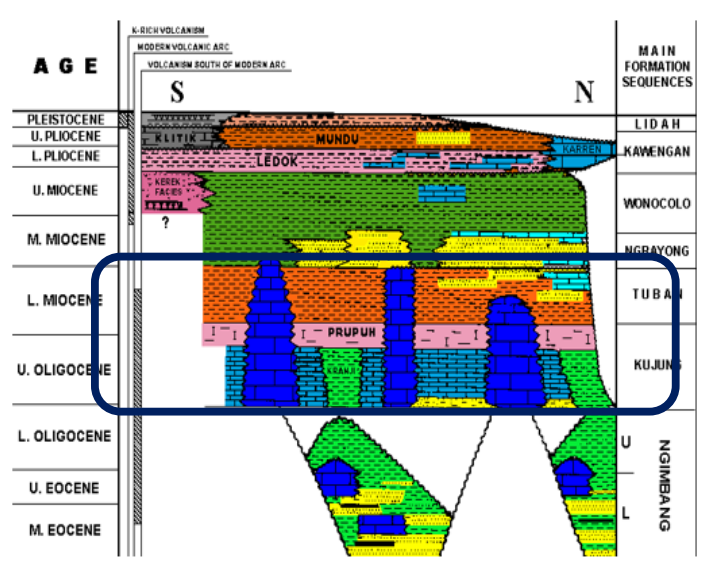

Gambar 1. Stratigrafi Daerah Penelitian. 
Untuk dapat mengkarakterisasi reservoir dengan baik, dilakukan studi dengan memanfaatkan data seismik dan data sumur. Dalam penelitian ini, metode yang digunakan adalah interpretasi kualitatif atribut seismik RMS dan inversi impedansi akustik untuk mengetahui properti fisis yang berkaitan dengan identifikasi zona hidrokarbon pada reservoir (Abdullah,2007).

\section{DASAR TEORI}

\section{A. Impedansi Akustik}

Impedansi akustik atau Acoustic Impedance (AI) merupakan sifat yang khas pada batuan yang merupakan hasil perkalian antar densitas $(\rho)$ dan kecepatan gelombang seismik (v). Secara matematis persamaan $\mathrm{Al}$ adalah sebagai berikut :

$$
A I=p v
$$

dengan keterangan:

$$
\begin{array}{ll}
\text { Al } & =\text { Impedansi Akustik }(\mathrm{ft} / \mathrm{s} . \mathrm{g} / \mathrm{cc}) \\
\rho & =\operatorname{densitas}(\mathrm{g} / \mathrm{cc}) \\
v & =\text { kecepatan gelombang seismik }(\mathrm{ft} / \mathrm{s})
\end{array}
$$

Perubahan nilai Al dapat menandakan perubahan karakteristik batuan seperti litologi, porositas kekerasan, dan kandungan fluida. Al dapat dianalogikan berbanding lurus terhadap kekerasan batuan dan berbanding terbalik dengan porositas.

\section{B. Metode Inversi}

Pada awalnya penerapan metode ini dimulai dengan asumsi model awal hasil picking yang dilakukan iterasi. Trace yang dihasilkan dari data sintetik akan dibandingkan dengan trace seismik asli sehingga didapatkan nilai error. Nilai error yang kecil menghasilkan solusi yang menyerupai keadaan aslinya. Dengan menggunakan data sintetik, diharapkan noise dalam seismik tidak akan mengganggu dalam proses inversi ini (Russel, 2008).

Secara matematis, model dan data pengukuran dapat dirumuskan sebagai berikut:

$$
\begin{aligned}
& M=\left(m_{1}, m_{2}, m_{3}, \ldots \ldots m_{k}\right)^{T} \\
& D=\left(d_{1}, d_{2}, d_{3}, \ldots \ldots d_{k}\right)^{T}
\end{aligned}
$$

dengan:

$M$ adalah model inversi,

D adalah data pengukuran lapangan.

Secara matematis $F$ dapat dituliskan sebagai berikut:

$$
F(M)=F\left(M_{0}\right)+\frac{\partial F\left(M_{0}\right)}{\partial M} \Delta M
$$

dengan:

$M_{0}$ adalah model dugaan awal,

$M$ adalah model bumi sebenarnya,

$\Delta M$ adalah perubahan parameter model,

$F(M)$ adalah data pengukuran,

$F\left(M_{0}\right)$ adalah harga perhitungan dari model dugaan $\frac{\partial F\left(M_{0}\right)}{\partial M} \Delta M$ adalah perubahan nilai perhitungan terhadap model.

\section{Seismik Atribut}

Brown (1999) mendefinisikan atribut seismik sebagai suatu informasi dasar derivatif dari data seismik. Informasi dasar yang dapat diturunkan dari data seismik adalah waktu, amplitudo, frekuensi dan atenuasi yang kemudian digunakan sebagai dasar klasifikasi atribut seismik (Gambar 2).

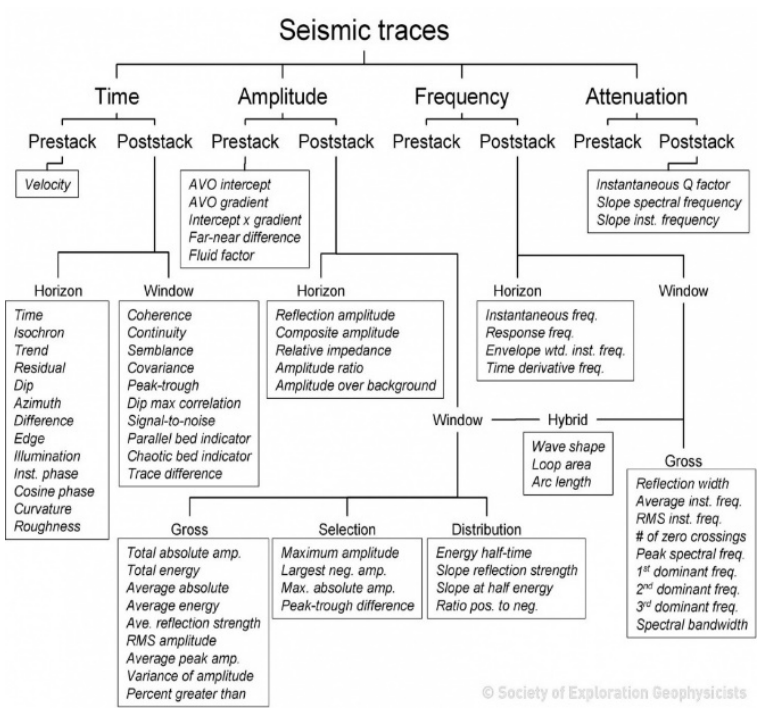

Gambar 2. Klasifikasi Seismik Atribut (Brown, 1999). 
Secara umum, atribut turunan waktu akan cenderung memberikan informasi perihal struktur, sedangkan atribut turunan amplitudo lebih cenderung memberikan informasi perihal stratigrafi dan reservoir. Atribut-atribut yang terdapat umumnya adalah atribut hasil pengolahan poststack yang dapat diekstrak sepanjang satu horizon atau dijumlahkan sepanjang kisaran window tertentu.

\section{Atribut Amplitudi RMS}

Salah satu sinyal seismik yang umummya digunakan untuk mendapatkan informasi reservoar adalah amplitudo. Pendekatan interpretatif untuk mengevaluasi reservoar dari atribut amplitudo menggunakan asumsi yang sederhana, yaitu bright spot pada peta seismik yang mendasarkan pada besar kecilnya amplitudo akan lebih tinggi bila saturasi hidrokarbon tinggi, porositas semakin besar, pay thickness lebih tebal (walaupun dengan beberapa komplikasi tuning effect) (Anggraini 2011).

Secara umum bahwa semakin terang bright spot (semakin nyata kontras amplitudo) maka semakin bagus prospeknya.

$$
R M S=\sqrt{\frac{1}{N} \sum_{i+1}^{N} a_{i}^{2}}
$$

Keterangan :

$$
\begin{array}{ll}
\mathrm{a} & =\text { amplitudo seismik } \\
\mathrm{N} & =\text { jumlah data }
\end{array}
$$

\section{METODE PENELITIAN}

Pada penelitian ini, data yang digunakan adalah:

a. data sumur sebanyakk 5 data yang memiliki deviasi dimana masing masing sumur memiliki data gamma ray, sonic, densitas dan beberapa memiliki checkshot dan top marker.

b. data seismik post-stack time migration 3D dengan kedalaman sampai $3000 \mathrm{~ms}$.

Proses pengolahan data diawali dengan analisa crossplot data log untuk mengetahui karakter dan lokasi kedalaman reservoar. Interpretasi horizon dilakukan pada top formasi tuban dan formasi karbonat dengan bantuan marker dari sumur dan informasi data log. Berikut adalah diagram alir dari penelitian ini:

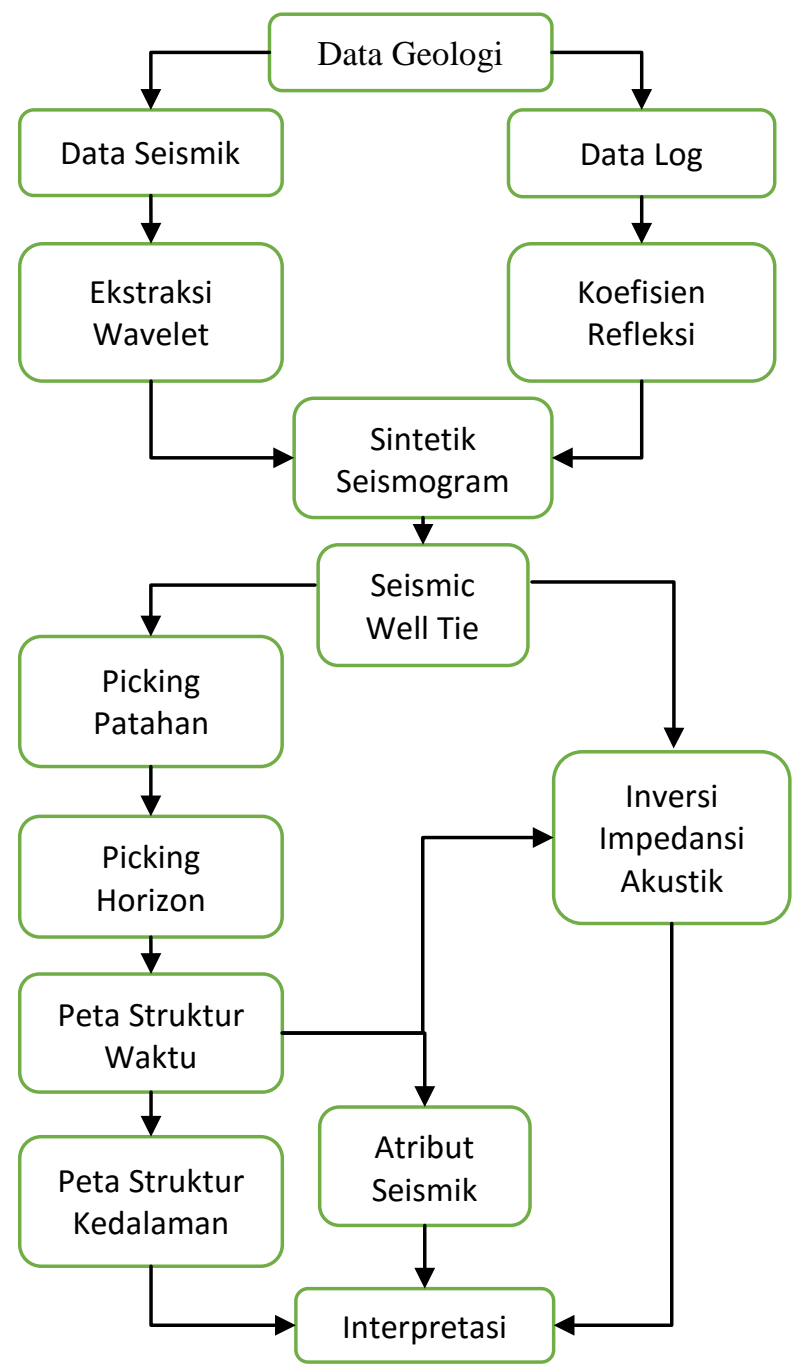

Gambar 3. Diagram Alir Penelitian.

Inversi impedansi akustik dan seismik atribut digunakan untuk menganalisa sifis lithologi dan keberadaan fluida hidrokarbon pengisi reservoar.

\section{HASIL DAN ANALISA}

\section{A. Analisa Crossplot}

Dilakukannya analisa data log ini berguna untuk menentukan marker top dan base reservoar di tiap masing masing sumur. Penentuan lokasi reservoir ini dapat dibantu oleh data log Gamma 
Ray, log Porositas, Density. Formasi yang menjadi reservoir di lokasi penelitian adalah Formasi Tuban Karbonat yang merupakan formasi batuan karbonat.

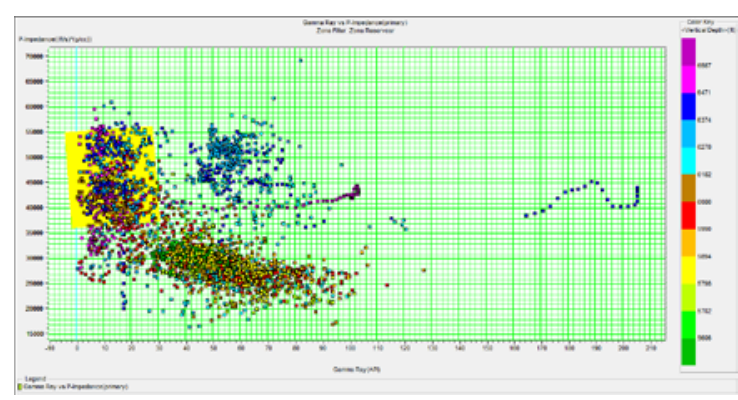

Gambar 4. Crossplot GR dengan P Impedance.

Dari hasil pengamatan crossplot log, reservoar karbonat ini yang direpresentasikan oleh gamma ray yang rendah tetapi bernilai impedansi tinggi (karena reservoir karbonat). Rata-rata kedalaman reservoir mulai pada kedalaman 6250 feet TVDSS.

\section{B. Seismik Well Tie}

Seismic Well Tie adalah proses pengikatan data seismik dengan data sumur yang bertujuan untuk menyamakan domain seismik yang dalam bentuk time ke dalam domain kedalaman dari data sumur. Tujuan akhir dari proses pengikatan ini adalah untuk mengetahui posisi atau horizon reservoar Tuban karbonat pada data seismik.

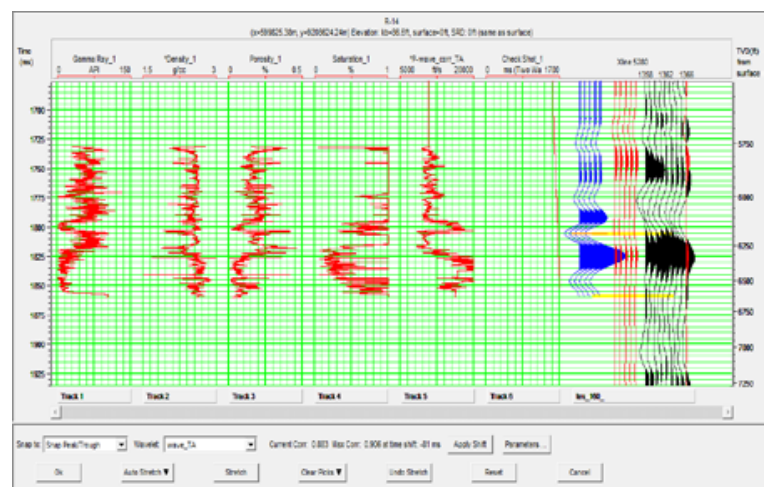

Gambar 5. Korelasi 0,742 pada Sumur R-1.4

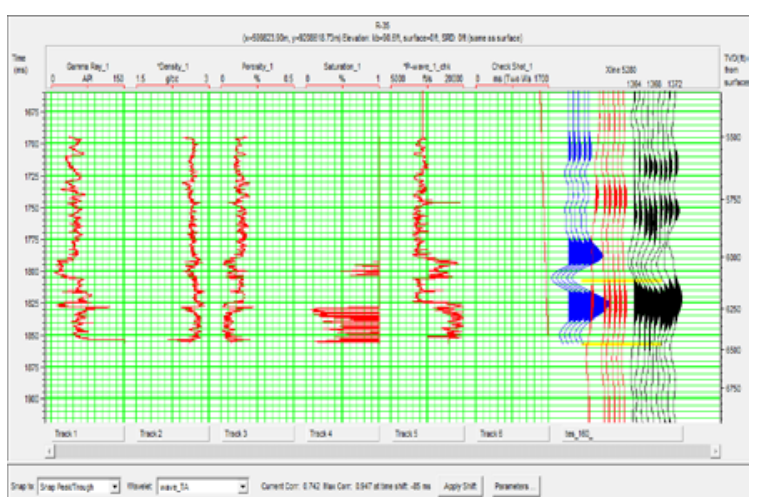

Gambar 6. Korelasi 0,883 pada Sumur R-35.

\section{Atribut Amplitudo RMS}

Analisa interpretatif untuk mengevaluasi reservoir dengan menggunakan atribut amplitude rms menggunakan asumsi besar kecilnya nilai amplitude yang sering disebut brightspot. Apabila semakin terang bright spot (semakin nyata kontras amplitudo) semakin bagus prospek hidrokarbon dalam wilayah tersebut karena semakin tinggi brightspot mengindikasikan tingginya saturasi hidrokarbon, porositas yang besar dan densitas yang kecil.

Dalam penelitian ini, horizon yang akan diterapkan atribut RMS adalah horizon Tuban karbonat yang merupakan reservoir dari zona interest. Warna hijau menunjukan nilai kontras amplitude yang besar sedangkan warna biru menunjukan amplitudo yang rendah Gambar 7 .

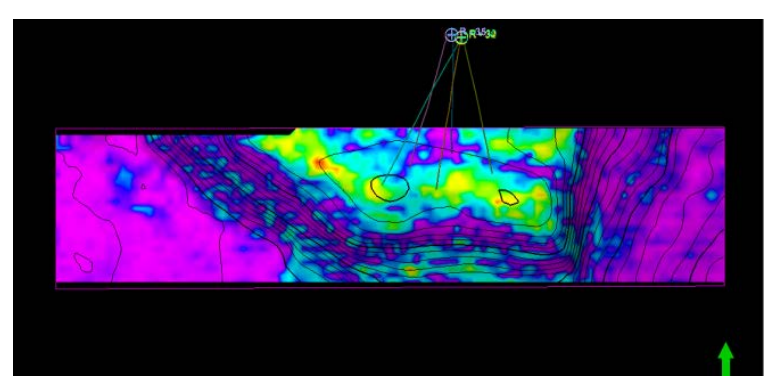

Gambar 7. Penerapan Atribut RMS pada Top Tuban Karbonat.

Dari hasil penerapan atribut RMS di atas, nilai RMS tinggi berkumpul pada puncak karbonat dan menyebar dari Barat ke Timur (daerah brightspot). Kemungkinan prospek hidrokarbon pada penelitian ini terdapat di sebelah Selatan dari puncak build up karbonat. Daerah tersebut telah terbukti memiliki 
prospek dengan dibuktikannya 2 sumur yang telah dibor.

\section{Analisis Model Inversi}

Proses inversi dilakukan pada karbonat reservoir Tuban. Data sumur kontrol dalam melakukan inversi adalah data sumur yang menembus seluruh formasi karbonat Tuban, yaitu sumur R-14 dan sumur R-35. Tujuan utama dari inversi adalah untuk melihat distribusi lateral dari nilai impedansi akustik berasal dari sumur.

Metode inversi yang digunakan adalah inversi Based Model. Metode ini dipilih karena metode ini menghasilkan inversi yang konsisten terhadap data seismik. Model awal yang digunakan adalah data dari properti sumur (Impedansi Akustik, Al) yang sudah terikat dengan data seismik yang dikontol oleh hasil interpretasi horison top dan bottom reservoir.

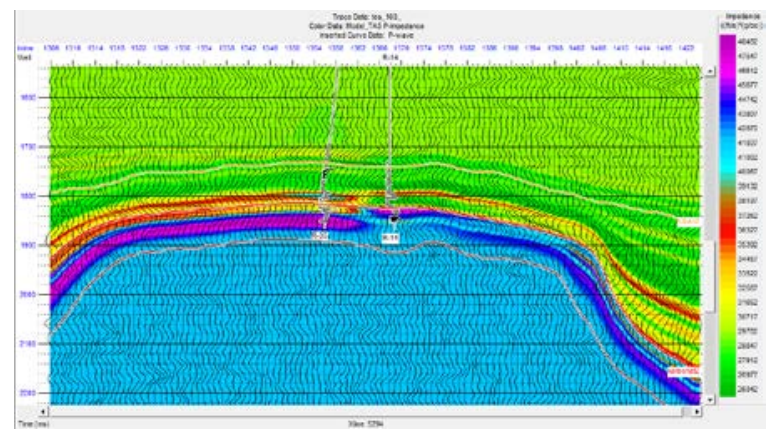

Gambar 8. Model Impedansi Akustik Hasil Interpolasi Data Al ke Data Seismik dengan Batasan Data Horizon.

\section{E. Inversi Impedansi Akustik}

Parameter yang digunakan dalam aplikasi inversi seismik Based Model ini antara lain sebagai berikut: hard constraint upper $=50 \%$, hard constraint lower 50\%, average block size $=2 \mathrm{~ms}$, prewhitening $=1 \%$, number of iteration $=10$.

Setelah parameter inversi ditentukan dan mendapatkan hasil error seminimum mungkin, kemudian dilakukan proses inversi pada seismik 3D pada formasi yang telah dibatas horizon.

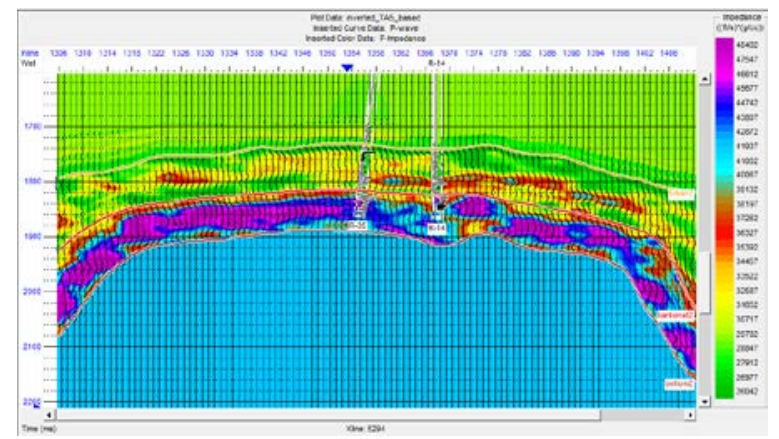

Gambar 9. Hasil Inversi Impedansi Akustik pada Lintasan xline 5294 yang Melalui Kedua Sumur.

Hasil inversi menunjukan bahwa Reservoar Karbonat pada lapangan penelitian mempunyai nilai impedansi yang tinggi yaitu 35392 - 48482 $\left((\mathrm{ft} / \mathrm{s})^{*}(\mathrm{~g} / \mathrm{cc})\right)$, dan terlihat potensi hidrokarbon pada reservoar dengan nilai impedansi 30717 $34645\left((\mathrm{ft} / \mathrm{s})^{*}(\mathrm{~g} / \mathrm{cc})\right)$ pada kedalaman 1800-1900 ms.

\section{F. Analisa dan Pembahasan}

Hasil dari analisa atribut RMS yang digunakan pada penelitian ini menunjukan adanya zona brightspot pada bagian antiklin S, SE dan SW. Zona Antiklin ini memang sangat baik digunakan untuk tempat akumulasi hidrokarbon bermigrasi. Hasil inversi impedansi akustik dari model ini menunjukan bahwa terdapat zona Al tinggi yang menunjukan bahwa zona reservoir merupakan lapisan karboat dengan intrusi zona impedansi rendah yang diindikasikan sebagai hidrokarbon pada zona reservoir.

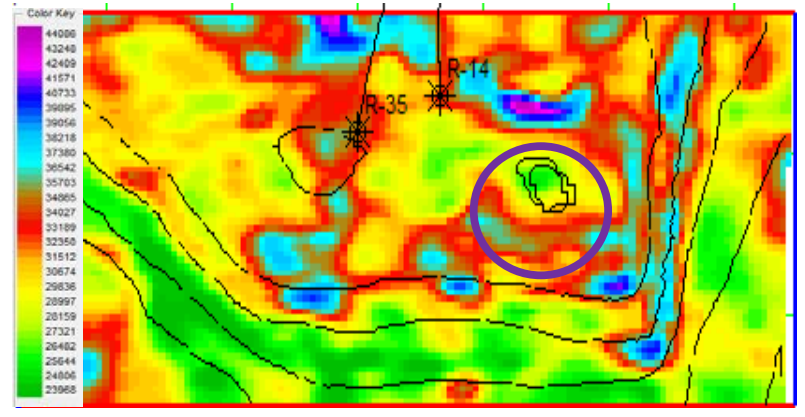

Gambar 10. Pengajuan Titik Pengeboran Baru (Lingkaran Biru). 
Berdasarkan hasil analisa struktur, atribut dan inversi impedansi akustik diajukan adanya 1 usulan titik (pengeboran baru karena pada lokasi tersebut memiliki zona brightspot dan nilai impedansi yang relative rendah sehingga berpotensi memiliki nilai porositas tinggi dan berisi hidrokarbon.

\section{PENUTUP}

\section{Kesimpulan}

Kesimpulan yang dapat diambil dari interpretasi seismik, log dan hasil inversi antara lain:

1. Dari analisa data log dan data seismik, didapatkan lokasi reservoir karbonat berada pada kedalaman rata rata $6200 \mathrm{ft}$ TVDSS.

2. Analisa depth structure maps membantu untuk melihat kemungkinan kedalaman dari reservoir.

3. Analisa Atribut Amplitudo RMS pada Top Reservoar Karbonat menunjukan zona brightspot yang mengindikasikan porositas tinggi dan hidrokarbon.

4. Reservoar Karbonat pada lapangan penelitian mempunyai nilai impedansi yang tinggi yaitu 35392 - $48482\left((\mathrm{ft} / \mathrm{s})^{*}(\mathrm{~g} / \mathrm{cc})\right)$, dan terlihat potensi hidrokarbon pada reservoar dengan nilai impedansi 30717 - $34645\left((\mathrm{ft} / \mathrm{s})^{*}(\mathrm{~g} / \mathrm{cc})\right)$ pada kedalaman 1800-1900 ms.

\section{Saran}

Saran dari hasil dan kesimpulan untuk membangun hipotesa-hipotesa selanjutnya antara lain perlu dilakukan analisa AVO, inversi impedansi elastik maupun LMR untuk karakterisasi reservoar lebih lanjut. Serta penambahan data sumur yang mencakup seluruh reservoar untuk inversi yang lebih akurat.

\section{UCAPAN TERIMA KASIH}

Penulis mengucapkan terima kasih kepada JOB Pertamina Petrochina East Java atas izin yang diberikan untuk mempublikasikan tulisan ini. Serta Ibu Wien, Pak Firman dan Mas Adi selaku pembimbing dalam menyusun tulisan ini.

\section{DAFTAR PUSTAKA}

Abdullah, Agus, 2007. Ensiklopedi Seismik. ensiklopediseismik. blogspot.com. Diakses pada hari Rabu, 9 Maret 2016, Pukul 11.01 WIB.

Anggraini, Tiara, 2011. Analisa Kualitatif Potensi Hidrokarbon Lapangan TA: DenganAplikasi Seismik Atribut, Tugas Akhir Program Sarjana, Universitas Indonesia.

Brown, R.A, 1999. Interpretation of Three-Dimensional Seismic Data Fifth Edition, AAPG Memoir 42.

Faisal, 2009. Prediksi Sebaran Porositas pada Lapisan Karbonat dengan Menggunakan Metode Inversi Berbasis Model pada Data Seismik3D, Skripsi, Universitas Hasanuddin

Hampson-Russell Software Service, Ltd., 2006. Strata: Theory and Exercises

JOB - Pertamina Petrochina East Java, 2013. Well Report.

Sukmono S, 2002. Interpretasi Seismik Refleksi. Departemen Teknik Geofisika, FIKTM, Institut Teknologi Bandung. 